\title{
Testimony and grammatical evidentials
}

Peter van Elswyk, University of Wisconsin-MilwaukeE

Penultimate draft · Forthcoming in Routledge Handbook of Social Epistemology

Testimony is typically offered with the use of a declarative sentence. But declaratives differ from one language to the next. Does testimonial practice differ cross-linguistically too? This chapter discusses grammatical evidentials to illustrate that it does. My illustration of the significance of evidentials to the epistemology of testimony has a negative and a positive part. For the negative part, it is argued that some definitions of testimony are mistaken because they do not apply to testimony offered by a declarative containing an evidential. The positive component discusses a new puzzle presented by McCready (2015) that evidentials raise about the justificatory status of testimony-based beliefs.

Keywords: testimony $\cdot$ evidentiality $\cdot$ testimony-based beliefs $\cdot($ not-)at-issue content

\section{Introduction}

Testimony is a social practice in which a speaker presents a proposition to a hearer who becomes positioned to accept that proposition because it was presented. At the center of a typical interaction is a declarative sentence. ${ }^{1}$ A speaker provides testimony by using a declarative. ${ }^{2}$ That declarative then expresses the proposition that a hearer may decide to accept.

But declaratives differ from one language to the next. Some contain tense, Mandarin declaratives do not. Some contain dedicated expressions that mark the sentence as declarative, English declaratives do not. Faced with variety, we should ask two questions.

\footnotetext{
${ }^{1}$ By declarative, I mean the sentence type with a proposition for its meaning that constrasts with the interrogative and imperative types (Sadock and Zwicky, 1985; König and Siemund, 2007). Some mean by indicative in the literature on testimony what I mean by declarative. But indicative has another use identifying a syntactic configuration that contrasts with a subjunctive configuration. To avoid confusion, I stick with declarative.

${ }^{2}$ In what follows, I forego discussion of the interplay between testimony and speech acts. Usually, though, testimony is characterized as being the product of an assertion and an assertion is what is performed by the use of a declarative. My reason for omission is that evidentials raise just as many questions about assertion as they do about testimony. For some discussion, see Faller (2002), Chung (2010), Velleman (2014), Murray (2017), and van Elswyk (2018).
} 
$\left(Q_{1}\right)$ Do the linguistic properties of a language's declarative make a difference to how testimony is socially practiced?

$\left(\mathrm{Q}_{2}\right)$ If so, are such differences in social practice relevant to the epistemology of testimony?

In this chapter, I answer both questions positively to show how cross-linguistic considerations are relevant to the epistemology of testimony. Unlike other sources of evidence like perception and memory, testimony is intimately related to language. That intimacy cannot be overlooked.

I make my case with declaratives containing EvidENTIALs. Evidentials are grammatical elements found in $25 \%$ of the world's languages that specify the source of evidence for a proposition expressed by a declarative (Aikhenvald, 2004). After explaining in $\S 2$ how testimony is practiced differently in languages with evidentials, I illustrate in $\S 3$ and $\S 4$ how these differences matter to the epistemology of testimony. ${ }^{3}$ My illustration has a negative and a positive part. For the negative part, it is argued that some definitions of testimony are mistaken because they do not apply to testimony offered by a declarative containing an evidential. The positive component discusses a new puzzle noted by McCready (2015) that evidentials raise about the justificatory status of testimony-based beliefs. I conclude in $§ 5$.

\section{Evidentiality}

The most basic unit of meaning is a morpheme. Some morphemes are words, some are not. For example, impossible consists of two morphemes: the word possible and the prefix -im. Evidentials are morphemes that specify a source of evidence. Consider an example in Cheyenne with an English translation from Murray $(2010,46)$.

\section{(1) É-némene-sèstse Sandy. Sandy sang, I hear(d).}

The evidential in the Cheyenne sentence is sestse. It appears as a suffix on the verb for singing. What it specifies is that the speaker has hearsay evidence for the proposition that Sandy sang.

Importantly, not all expressions about evidence source are evidentials. Though most languages have expressions about evidence, languages only have evidentials when their grammar contains evidentiality as a category (Aikhenvald, 2004; Speas, 2008). For example, English has adverbs like allegedly and parenthetical verbs like $I$ heard, but these expressions are not evidentials. An apt parallel is

3 The explanation of evidentiality that I provide is tailored to highlight its significance to testimony. For more expansive introductions, I recommend the reader begins with Aikhenvald (2004), Speas (2008), and Murray (2017). 
tense. Though most languages have expressions to specify the time at which an event occurs, not all languages contain tense.

That evidentials belong to a grammatical category is significant. Morphemes belonging to a grammatical category can sometimes be obligatory. Consider tense again. Declaratives are ungrammatical in English without a tense morpheme specifying the time at which the verb's event occurs. Compare Pim smile and Pim smiled. The first is uninterpretable but the second is interpretable because it contains the past tense morpheme $-d$. In some languages with evidentiality, a declarative is similarly ungrammatical when it lacks an evidential. As Aikhenvald (2004, 1-2) notes:

Tariana, an Arawak language spoken in the multilingual area of the Vaupés in northwest Amazonia, has an even more complex system. In this language, one cannot simply say 'José played football'. Just like in all other indigenous languages from the same area, speakers have to specify whether they saw the event happen, or heard it, or know about it because somebody else told them, etc. This is achieved through a set of evidential markers fused with tense. Omitting an evidential results in an ungrammatical and highly unnatural sentence.

The signifiance of evidentials to testimonial practice is therefore immediate. In languages with obligatory evidentials, speakers are not capable of providing testimony by using a declarative without disclosing the source of their information. Merely stating how things are is impossible.

But how does a declarative with an evidential convey the speaker's evidence source? Taking the tense parallel too seriously tempts the conclusion that languages with obligatory evidentials limit speakers to only saying propositions about their evidence sources. Tense places limits on what can be said, after all. But evidentials are different. A use of a declarative can express many propositions because of the expressions it contains. An expressed proposition is AT-ISSUE when it is the sentences's main point or primary contribution. Being at-issue contrasts with being NOT-AT-ISSUE which is the status content has when it is expressed but backgrounded. Examples of not-at-issue content include presuppositions triggered by verbs like stopped and conventional implicatures conveyed by expressions like therefore. ${ }^{4}$ Evidentials are similar in that they contribute not-at-issue content distinct from that expressed by the declarative's main clause. ${ }^{5}$ Reconsider (1). It expresses two propositions: that Sandy sang, the proposition associated with the main clause, and that the speaker heard that Sandy sang, the proposition contributed by the evidential.

To illustrate, an important diagnostic for being at-issue is being directly challengeable with replies like That's false (Tonhauser, 2012). But the contri-

4 Potts (2004), Tonhauser et al. (2013), and Horn (2016) provide taxonomies of not-at-issue content. See Simons et al. (2010), Murray (2014, 2017), Syrett and Koev (2015), Hunter and Asher (2016), and Frazier et al. (2018) for theories of the (not-)at-issue distinction.

5 See Murray (2010, 2014, 2017), Izvorski (1997), Faller (2002), Matthewson et al. (2007), and Krawczyk (2009). 
bution of an evidential is never directly challengeable. Korotkova $(2016,66)$ observes that "Based on the data from available studies of evidentiality... the non-challengeability of the [evidential's contribution] is a universal property of morphological evidentials." The only proposition targetable is the one contributed by the main clause. Here are some examples in Cuzco Quechua from Faller (2006, 157-158) where the demonstrative that is used to target different propositions with varying success.

(2) Ines-qa qaynunchay ñaña-n-ta-s watuku-sqa. AT-ISSUE: Inés visited her sister today. NOT-AT-ISSUE: Speaker was told that Inés visited her sister today.

(3) Mana-n chiqaq-chu. Manta-n-ta-lla-n watuku-rqa-n. That's not true. She only visited her mother.

(4) Mana-n chiqaq-chu. \#Mana-n chay-ta willa-rqa-sunki-chu. That's not true. \#You were not told this.

(3) and (4) are replies to (2). The reply in (3) is acceptable. That targets the at-issue proposition while the speaker disagrees that Inés visited her sister. In contrast, (4) is not acceptable because it attempts to target the not-at-issue proposition to disagree that the speaker heard as much.

Standardly, evidentials are categorized according to whether they specify that the speaker has direct or indirect evidence for the at-issue proposition. Direct evidentials specify that the speaker has perceptual evidence (e.g. sight, sound) while indirect evidentials specify that the speaker's evidence is mediated (e.g. inferred, hearsay). Cross-linguistic variation is found in the number of evidentials a language has and which sources receive a dedicated evidential (Willett, 1988; Aikhenvald, 2004). Some like Cherokee only have evidentials coarsely marking whether the source is direct or indirect (Pulte, 1985). Others have a more fine-grained system. Tariana has direct evidentials for information sourced visually or non-visually and indirect evidentials for information that was inferred, assumed, or reported (Aikhenvald, 2004).

Speakers of many languages with evidentials consider some sources to be weaker or less reliable than others. As Givón $(2005,169)$ puts it, "evidential markers code primarily the evidential source that can back up an assertion and... indirectly, the strength or reliability of that evidence." ${ }^{6}$ To explain speaker judgments about strength, scales like Figure 1 are frequently found in the linguistics literature. ${ }^{7}$

${ }^{6}$ It is an open question how evidentials are associated with judgments about the reliability of an evidence source. That association could be coded into the meaning of evidentials or it could be the result of a pragmatic inference. For various perspectives on this issue, consult Faller (2012), Krawczyk (2009), Davis et al. (2007), Northrup (2014), McCready and Ogata (2007), McCready (2015), and Murray (2017).

7 See Givón (1982, 2005), Barnes (1984), Willett (1988), Chafe and Nichols (1996), Faller (2002, 2012), and Davis et al. (2007). 


\section{STRONGER $\longleftrightarrow$ WEAKER \\ Visual $\cdot$ Nonvisual $\cdot$ Inferential $\cdot$ Hearsay \\ Figure 1}

Fundamental facts about the nature of evidence may not be reflected in Figure 1. However, what Figure 1 does reflect is that an evidential can sometimes determine the strength with which the at-issue proposition is recommended by a speaker. ${ }^{8}$ For example, perception licenses the use of both a direct evidential and an inferential evidential because a speaker can draw inferences about her experience. In choosing which to use, speakers often base their selection based on how forcefully they want to stand behind the at-issue proposition. A speaker choosing to stand behind a proposition less uses an inferential evidential. Otherwise, she uses a perceptual evidential.

We can observe the difference that evidentials make to strength by considering what happens when a speaker follows the presentation of an at-issue proposition with a disavowal of belief in that proposition. In English, disavowing belief in the at-issue proposition expressed by an unqualified declarative is Moorean paradoxical (Moore, 1962).

(5) \# Pim smiled, but I don't believe it.

Declaratives with evidentials specifying a source that is considered strong are similarly infelicitious. However, evidentials specifying a source that is considered weak can be followed by a disavowal in some languages. Hearsay evidentials are the prime example. Below is another illustration in Cuzco Quechua from Faller (2002, 194).

(6) Para-sha-n-si, ichaqa mana crei-ni-chu.

It is raining (I heard), but I don't believe it.

The speaker in (6) presents the at-issue proposition that it is raining and specifies that her evidence is hearsay. Then she immediately states without infelicity that she does not believe what she overheard.

Evidentials therefore influence testimonial practice in another striking way. Depending on the evidence source that is specified, the strength with which the speaker recommends the at-issue proposition varies. Testimony sourced directly in the speaker's own experience is regarded as stronger than testimony sourced indirectly. ${ }^{9}$ Consequently, how a hearer is positioned to respond to testimony

\footnotetext{
${ }^{8}$ I hedge with sometimes because not every language with evidentiality as a grammatical category allows their use to influence strength or force. Aikhenvald $(2004,6, f n .1)$ notes that it depends on the size of an evidential system and the number of expressions within that system. The examples given in this paper are from languages where fieldwork has confirmed that evidentials do influence strength.

${ }^{9}$ Hedges like Pim smiled, I heard behave similarly in English. See Benton and van Elswyk (2018) for discussion.
} 
varies with the oomph of the speaker's recommendation. Hearers offered only testimony backed by hearsay, for example, may want to suspend judgment until they receive testimony backed by a stronger source.

Altogether, I have identified two major ways in which testimonial interactions are distinct because of evidentiality. The first is that a speaker always conveys a not-at-issue proposition about her evidence for the at-issue proposition. The second is that the strength of the testimony varies depending on which source is specified by the not-at-issue proposition. Atop these features of testimonial practice other conventions and norms take shape. To pick one example, evidentiality informs how trustworthiness is determined. A speaker's reliability can be measured by whether she accurately uses evidentials or not. As a consequence, speakers whose native language has obligatory evidentials often mistrust what other speakers say in another language that does not have obligatory evidentials. Aikhenvald $(2004,343)$ reports, for example, that "Indians of the Vaupés area complain that when non-Indians speak Portuguese they are not explicit enough and often "lie."

\section{Testimony as source}

Having seen how testimonial practice is different in languages with evidentials, we turn to its epistemology. ${ }^{10}$ Most theorizing about testimony is informed by cases where it is offered by speakers using unqualified declaratives like Pim smiled. Let's call testimony offered by an unqualified declarative UNQUALIFIED TESTIMONY and use EVIDENTIAL TESTIMONY to name testimony that a speaker offers by using a declarative with a grammatically obligatory evidential. In this section, I show how considering only unqualified testimony has produced mistakes in how some demarcate testimony as a source.

Definitions of testimony are either broad, narrow, or somewhere in the middle (Lackey, 2008). Having few conditions on what testimony is, broad definitions count many acts as sources of testimony. Narrow definitions countenance fewer acts as testimony by having more conditions. Common to various moderate and narrow definitions is what I call an OFFERING CONDITION. An offering condition requires that a speaker's saying a proposition is presented as evidence for that proposition. The condition is explicit in the first condition of the narrow definition provided by Coady $(1992,42)$.

\section{$\left(\mathrm{C}_{1}\right) S$ stating that $p$ is evidence that $p$ and is offered as evidence that $p$.}

It is also explicit in the first condition of a weaker definition that Graham (1997, 227) offers.

${ }^{10}$ My discussion of testimony is limited to showcase the significance of evidentiality to its epistemology. For more thorough introductions, see Lackey (2010), Adler (2015), Gelfert (2014), and citations therein. 
$\left(\mathrm{G}_{1}\right) S$ s stating that $p$ is offered as evidence that $p$.

The condition is implicit in many understandings of testimony as well. When Burge $(1993,467)$ glosses testimony as an act where a proposition is "presented as true" by a rational speaker, he appears to assume that the speaker's expressing $p$ is regarded as evidence for $p$. Similarly, Moran $(2005,15)$ does not offer outright a definition of testimony, but he says that what separates testimony from other linguistic acts is that, in testimony, the speaker is "presenting his utterance as a reason to believe" a proposition.

The problem with an offering condition is that it does not apply to all instances of evidential testimony. In $§ 2$, we learned that an evidential declarative expresses an at-issue proposition (call it $p$ ) and a not-at-issue proposition about the speaker's source of evidence for the at-issue proposition (call it $q$ ). That means the speaker is always offering $q$ as evidence for $p$ in evidential testimony. As a result, we can distinguish two ways that a speaker can support a proposition through an act of testimony.

DOUBLE-BARRELED SUPPORT SINGLE-BARRELED SUPPORT

Both $S$ 's stating that $p$ and $S$ 's Only $S$ 's stating that $q$ is evidence stating that $q$ are evidence for $p$. for $p$.

What double-barreled and single-barreled support have in common is that $q$ is offered as evidence for $p$. But they differ on whether the speaker's stating that $p$ is also offered as evidence for $p$. Since only $q$ is offered as evidence for $p$ with single-barreled support, an offering condition cannot apply to evidential testimony backed with single-barreled support.

Let's consider a concrete example. In some languages with grammatical evidentials, they can appear in interrogatives as well as declaratives (Aikhenvald, 2004; Speas, 2008). When they appear in interrogatives, the evidential does not specify the speaker's source of evidence. Instead, the evidential contrains what evidence source the hearer can specify in an answer. Here is an example in Cheyenne from Murray $(2017,87)$.

(7) Tósáe é-hoé-sèstse Annie

Given what you heard, where does Annie live?

As a result of the evidential, (7) cannot be sincerely answered by a hearer unless she can support her answer with hearsay evidence. With this feature of evidentials in view, consider the following hypothetical situation between two speakers of Cheyenne.

HESITANT CHELSEA

Chelsea has no beliefs about where Annie lives. She is skeptical of propositions for which she does not have direct evidence and her only evidence concerning Annie's residence is hearsay that she lives on George Street. So Chelsea is suspending judgment until her epistemic position improves. 
But Rebecca, a mutual friend, asks Chelsea to state where Annie lives given what she heard. Chelsea would not normally volunteer such information because she does not believe it. Still, she cooperates with Rebecca's request by answering that she heard (sestse) that Annie lives on George Street. To ensure that Rebecca knows her own attitude on the question, Chelsea quickly follows her answer by disavowing belief.

In such a case, Chelsea is not offering her statement that Annie lives on George Street as evidence. Murray $(2017,72)$ describes sestse, the hearsay evidential, as not "commit[ting] the speaker at all to the truth or the possibility of the atissue proposition" expressed by a declarative. So Chelsea cannot be understood as supporting the proposition that Annie lives on George Street. Her disavowal of belief underscores her lack of support. Nevertheless, Chelsea still testifies that Annie lives on George Street. By disclosing that she has hearsay evidence, Chelsea enables Rebecca to make up her own mind. If she is less skeptical about hearsay evidence than Chelsea, Rebecca could come to believe that Annie lives on George Street on the basis of Chelsea's answer.

The particular lesson to learn is that definitions of testimony cannot possess an offering condition. Though such a condition may aptly characterize unqualified testimony, it does not apply to evidential testimony with singlebarreled support. So broader characterizations of testimony are better suited to apply to evidential and unqualified testimony alike. The definition in Fricker (1994, 396) of testimony as "tellings generally" will do, but so will less broad definitions that lack an offering condition. ${ }^{11}$ The general lesson to learn is methodological. Mistakes about testimony will be made if we are not attentive to practice differences caused by language.

\section{Testimony-based beliefs}

Once testimony has been demarcated as a source, the natural epistemological question to ask is how beliefs based upon testimony are justified. On one side, there are REDUCTIONISTS. They maintain a hearer's testimony-based beliefs are justified only through other sources available to the hearer (e.g. memory, perception, induction). ${ }^{12}$ On the other side, NON-REDUCTIONISTS maintain that testimony-based beliefs have independent justification. ${ }^{13}$ A proposition's being testified is sufficient justification for a hearer's belief. In between reductionism and anti-reductionism are various hybrid positions. ${ }^{14}$ This section motivates that evidential testimony presents new considerations relevant to understanding the justificatory status of testimony-based beliefs.

11 Definitions that fit this description include those given by Lackey (2008) and Cullison (2010).

12 Reductionism has its roots in David Hume. The leading defender is Fricker (1994).

13 An early non-reductionists was Thomas Reid. Among others, contemporary defenses of nonreductionism are offered by Coady (1992), Burge (1993), Moran (2005), and Graham (2010). ${ }^{14}$ Prominent hybrid positions are found in Lackey (2008) and Faulkner (2011). 
Depending on one's view, different advice will be given about how to respond to testimony. Reductionists and hybrid views will provide you with a checklist to resolve before you accept what is testified. For example, they may want to know whether the speaker providing the testimony is reliable in your experience. Nonreductionists will not present you with a checklist. As long you do not have prior reasons for not accepting what was testified, you are justified in accepting the testified proposition. Let's distill this advice as the following principle inspired by Burge (1993).

\section{ACGEPTANCE PRINCIPLE (AP)}

We are justified in accepting anything that we are told unless there is positive evidence against accepting what we are told.

Importantly, AP is not limited to the at-issue proposition expressed by the declarative used to offer testimony. Nor should it be. A sentence can express many propositions and a hearer is just as positioned to accept one as she is to accept any other. That one proposition is at-issue while the others are not does not make a difference to a hearer's ability to learn.

But most not-at-issue content is not about the at-issue content. Presuppositions are not, for example. So evidential testimony is unique. It puts the hearer in a position where she can learn about the epistemic status of the at-issue proposition from the not-at-issue proposition contributed by the evidential. What the hearer learns might then influence whether she decides to accept the at-issue proposition. That can lead to situations where a hearer both has reason to accept and not to accept the at-issue proposition. McCready (2015, 260261 ), one of the few to consider the epistemological significance of evidentality, observes that evidential testimony generates that paradoxical situation when an unreliable source is specified.

Suppose that the speaker has a choice between asserting $\operatorname{Dir} \phi$ and $\operatorname{Rep} \phi$ (from some direct evidential Dir and hearsay evidential Rep). Rep $\phi$ requires a weaker justification than $\operatorname{Dir} \phi$ and is likely to be less reliable. Thus, given that the speaker asserted $\operatorname{Rep} \phi$ rather than $\operatorname{Dir} \phi$, we can conclude... that she was not sufficiently confident in her justification to assert $\operatorname{Dir} \phi \ldots$ But then... it does not appear to be reasonable for the hearer to add $\phi$ to her stock of beliefs. But... the Acceptance Principle tells us that $\phi$ should be accepted, given that there are no confounders. Thus the fact that the speaker proffers $\phi$ will be enough to justify the hearer coming to believe that $\phi$.

Let's call this the ACCEPTANCE PUZzLE. Those favoring reductionist or hybrid theories of testimonial justification have an easy solution. They will deny AP because more is needed for justification than what AP requires. But what solutions are available to the non-reductionist?

One option is to restrict AP only to propositions for which the speaker has direct evidence. McCready (forthcoming) proposes such a solution by endorsing a principle we can reconstruct as $\mathrm{AP}_{\mathrm{R}}$. 
ACCEPTANCE PRINCIPLE RESTRICTED $\left(\mathrm{AP}_{\mathrm{R}}\right)$

We are justified in accepting anything the speaker says that she acquired directly unless there is positive evidence against accepting what we are told.

Supplanting AP with $\mathrm{AP}_{\mathrm{R}}$ solves the acceptance puzzle. That is because $\mathrm{AP}_{\mathrm{R}}$ does not justify a hearer in accepting $\phi$ on the basis of testimony taking the form $R e p \phi$. We are only justified in believing $\phi$ on the basis of testimony when the speaker's source of evidence for $\phi$ is direct.

But this solution comes with a steep cost. It renders a huge swathe of testimony-based beliefs unjustified. As Martini (forthcoming) notes, beliefs based in hearsay include those developed in response to oral history, those students learn from what teacher report from textbooks, those formed by young children about the meanings of words, those about the distant past, and more. Though some non-reductionists may be willing to rid many testimonybased beliefs of their justification, I doubt most will want to. Reductionism is frequently criticized on the grounds that it cannot justify enough testimonybased beliefs (Coady, 1992; Adler, 2002; Lackey, 2008). Non-reductionists wary of underjustifying many of our beliefs should similarly not favor $\mathrm{AP}_{\mathrm{R}}$.

Denying that hearsay evidence is weak might seem to be the most straightforward solution available to the non-reductionist. If non-reductionism is true, after all, the speaker's source of evidence is irrelevant to testimonial justification. That the testified proposition is backed by hearsay arguably provides extrajustification as well. It means that the belief is supported by a chorus of testifiers who have checked it against their own knowledge.

A cost accompanies this solution as well. Though the view that hearsay evidence is weak is not unique to languages with evidentials, evidentiality integrates the view into language in a unique way. ${ }^{15}$ As we learned in $\$ 2$, the weakness of hearsay follows from the strength scale of Figure 1 that reflects speaker judgments. So maintaining that testimony backed by hearsay is strong as opposed to weak entails that speakers of languages with evidentials systematically err. I did not take a side in $\$ 2$ on whether information about the strength of an evidence source was part of the semantic content of an evidential or a pragmatic inference made by hearers. ${ }^{16}$ But suppose it is semantic such that part of the notat-issue content contributed by an evidential is that the source specified is weak. Then the non-reductionist must conclude that speakers cannot specify that they have hearsay evidence without saying something false. They may truthfully say $R e p \phi$, but they falsely say that $R e p$ is weak.

That cost snowballs into another. Many non-reductionists begin by identifying what our testimonial practices are and then finish by explaining why those practices are epistemically responsible (Coady, 1992; Graham, 2000).

${ }^{15}$ Consider, for example, the hearsay evidence rule found in many legal systems. For some discussion of the rule, see Coady (1992) and Gelfert (2014). $\quad{ }^{16}$ See fn.6. 
For example, acceptance is the default response to unqualified testimony if a hearer does not have prior reason to doubt the speaker. A principle like AP accounts for why that response is not irresponsible. But we have seen that evidential testimony with a hearsay evidential is not associated with the same defaults. The testimonial practices are different in languages with evidentials. So to hold that speakers of languages with evidentials systematically err betrays the methodology. A non-reductionist wanting to be consistent in this methodology will therefore need to somehow accommodate that hearsay is weak.

Let's consider one final response. The non-reductionist might argue that there is no puzzle in the first place. AP states that acceptance is justified unless there is positive evidence against accepting what we are told. So maybe evidential testimony is just unusual in that the positive evidence against accepting the atissue proposition can be learned from the not-at-issue proposition expressed in that very act of testimony. In other words, the situation McCready describes is not paradoxical because the hearer can accept the not-at-issue proposition that the speaker has hearsay evidence, as advised by AP, but not accept the at-issue proposition because she now has positive evidence that the speaker's evidence for the at-issue proposition is weak.

Nevertheless, there remains good reason for thinking that the non-reductionist is confronted with a puzzle. Consider what the hearer does not learn from the not-at-issue proposition. She does not learn that the at-issue proposition is false or that speaker has evidence that it is false. She does not learn that the speaker is untrustworthy, deceptive, or confused. Instead, what she learns is that the speaker learned the at-issue proposition through testimony. That is not positive evidence against accepting what was said. It is exactly the opposite. If the speaker learned the at-issue proposition through testimony, then, given AP, the speaker was justified in accepting the at-issue proposition. The hearer should likewise be justified in accepting that proposition. And yet, the fact that the speaker used a hearsay evidential as opposed to a direct evidential signals that the speaker does not have stronger evidence with which to support the at-issue proposition. As a result, the hearer has reason to not accept the at-issue proposition in this situation. In the words of McCready $(2015,261)$, "we now have two inferential chains which lead to contradictory conclusions."

Perhaps the non-reductionist can do better than the three responses I have considered. ${ }^{17}$ My aim in discussing the puzzle was not to argue against nonreductionism. It was to showcase how evidential testimony raises new issues in the epistemology of testimony. What we have seen is that evidential testimony supported by hearsay does exactly that. It generates a puzzle that does not have an easy solution.

17 McCready (2015) offers another solution that I do not discuss for reasons of space. That solution comes in the form of a dynamic semantics for evidentials. One may wonder, though, whether an epistemic puzzle can be solved with a semantics. 


\section{Conclusion}

In showing how evidentiality in particular makes a difference to how testimony can be understood, I have only scratched the surface. There are many more questions about testimony that are raised by evidentials. Still, this chapter has made a case for the importance of cross-linguistic considerations to the epistemology of testimony. Like many corners of philosophy, theorizing about testimony often treats English as the lingua franca. But that assumption can only get us so far. If we want to understand testimony as an act and source available in every language, we need to attend to how it is practiced differently in some societies because of the language spoken. 


\section{References}

Adler, Jonathan. 2002. Belief's Own -. 2012. "Evidential scalar implicaEthics. MIT Press.

-. 2015. "Epistemological Problems of Testimony." The Stanford Encyclopedia of Philosophy .

Aikhenvald, Alexandra. 2004. Evidentiality. Oxford University Press.

Barnes, Janet. 1984. "Evidentials in the Tuyuca verb." International Journal of American Linguistics 50:255-271.

Benton, Mathew and van Elswyk, Peter. 2018. "Hedged Assertion." In Sandy Goldberg (ed.), Oxford Handbook of Assertion. Oxford University Press.

Burge, Tyler. 1993. "Content Preservation.” The Philosophical Review 102:457488.

Chafe, W. and Nichols, J. 1996. Evidentiality: The Lingusitic Coding of Epistemology. Norwood, NJ: Ablex.

Chung, Kyung-Sook. 2010. "Korean evidentials and assertion." Lingua 120:932952.

Coady, C.A.J. 1992. Testimony: A Philosophical Study. Oxford University Press.

Cullison, Andrew. 2010. "On the Nature of Testimony.” Episteme 7:114-127.

Davis, Christopher, Potts, Christopher, and Speas, Peggy. 2007. "The pragmatic values of evidential sentences." Proceedings of SALT 17:72-88.

Faller, Martina. 2002. Semantics and Pragmatics of Evidentials in Cuzco Quechua. Ph.D. thesis, Stanford University.

—. 2006. "Evidentiality below and above speech acts." tures." Linguistics and Philosophy 35:285312 .

Faulkner, Paul. 2011. Knowledge on Trust. Oxford University Press.

Frazier, Lyn, Dillon, Brian, and Clifton, Charles. 2018. "Together They Stand: Interpreting Not-at-Issue Content." Language and Speech 62:199-226.

Fricker, Elizabeth. 1994. "Against Gullibility." In A. Chakrabarti and B.K. Matilal (eds.), Knowing from Words. Kluwer.

Gelfert, Axel. 2014. A Critical Introduction to Testimony. Bloomsbury Critical Introductions to Contemporary Epistemology. Bloomsbury.

Givón, T. 1982. "Evidentiality and Epistemic Space.” Studies in Language 6.

-. 2005. Context as Other Minds: The Pragmatics of Sociality, Cognition and Communication. John Benjamins.

Graham, Peter. 1997. "What is testimony?” Philosophical Quarterly 187:227232.

-. 2000. "The Reliability of Testimony." Philosophy and Phenomenological Research 61:695-709.

-. 2010. "Testimonial Entitlement and the Function of Comprehension." In Alan Millar and Adrian Haddock (eds.), Social Epistemology. Oxford University Press.

Horn, Larry. 2016. "Information Structure and the Landscape of (Not)At-issue Meaning." In Caroline Fery and Shinichiro Ishihara (eds.), Oxford Handbook of Information Structure. Oxford University Press. 
Hunter, Julie and Asher, Nicholas. 2016. "Shapes of Conversation and At-issue Content." Semantics and Linguistics Theory 26:1022-1042.

Izvorski, Roumyana. 1997. "The present perfect as an epistemic modal." Proceedings of SALT 12 222-239.

König, E. and Siemund, P. 2007. "Speech act distinctions in grammar." In T. Shopen (ed.), Language Typology and Syntactic Description, volume 1. Cambridge University Press.

Korotkova, Natalia. 2016. "Disagreement with evidentials: A call for subjectivity." In Julie Hunter, Mandy Simons, and Matthew Stone (eds.), JerSem: The 20th Workshop in the Semantics and Pragmatics of Dialogue, 65-75.

Krawczyk, Elizabeth. 2009. "Do you have evidence for that evidential?" In Corinne Hutchinson and Elizabeth Krawczyk (eds.), Theoretical Approaches to Understudied Languages, volume 7.

Lackey, Jennifer. 2008. Learning from Words: Testimony as a Source of Knowledge. Oxford University Press.

-. 2010. "Testimony: acquiring knowledge from others." In Alvin Goldman and Dennis Whitcomb (eds.), Social Epistemology: Essential Readings. Oxford University Press.

Martini, Francesco. forthcoming. "Hearsay viewed through the Lens of Trust, Reputation and coherence." Synthese .

Matthewson, Lisa, Rullmann, Hotze, and Davis, Henry. 2007. "Evidentials as epistemic modals." The Linguistic Variation Yearbook 7:201-254.

McCready, Elin. 2015. Reliability in Pragmatics. Oxford University Press.
-. forthcoming. "Testimony, trust, and evidentials." In Chung-Min Lee and Jinho Park (eds.), Evidentials and Modals. Leiden: Brill.

McCready, Elin and Ogata, N. 2007. "Evidentiality, Modality, and Probability." Linguistics and Philosophy 30:147206.

Moore, G.E. 1962. Commonplace Book: 1919-1953. London: George Allen and Unwin.

Moran, Richard. 2005. "Getting told and being believed.” Philosophers' Imprint 5:129.

Murray, Sarah. 2010. Evidentiality and the Structure of Speech Acts. Ph.D. thesis, Rutgers University, New Brunswick.

-. 2014. "Varieties of Update." Semantics and Pragmatics 7:1-53.

-. 2017. The Semantics of Evidentials. Oxford: Oxford University Press.

Northrup, Oliver. 2014. Grounds for Commitment. Ph.D. thesis, UC Santa Cruz.

Potts, Christopher. 2004. The Logic of Conventional Implicatures. Oxford University Press.

Pulte, W. 1985. "The experienced and nonexperienced past in Cherokee." International Journal of American Linguistics 51:543-544.

Sadock, Jerrold and Zwicky, Arnold. 1985. "Speech act distinctions in syntax." In Timothy Shopen (ed.), Language Typology and Syntactic Description, 155-196. Cambridge University Press.

Simons, Mandy, Tonhauser, Judith, Beaver, David, and Roberts, Craige. 2010. "What projects and why." Proceedings of SALT 20 309-327. 
Speas, Margaret. 2008. "On the syntax and semantics of evidentials." Language and Linguistics Compass 2:940-965.

Syrett, Kristen and Koev, Todor. 2015. "Experimental Evidence for the Truth Conditional Contribution and Shifting Informational Status of Appositives." Journal of Semantics 32:525-577.

Tonhauser, Judith. 2012. "Diagnosing (not-)at-issue content." Proceedings of Semantics of Under-represented Languages of the Americas 6:239-254.
Tonhauser, Judith, Beaver, David, Roberts, Craige, and Simon, Mandy. 2013. "Toward a taxonomy of projective content." Language 89:66-109.

van Elswyk, Peter. 2018. Un/qualified declaratives. Ph.D. thesis, Rutgers University, New Brunswick.

Velleman, J. David. 2014. "Doables." Philosophical Explorations 17:1-16.

Willett, Thomas. 1988. "A Crosslinguistic survey of the grammaticization of evidentiality." Studies in Language 12:51-97. 